\title{
Late sucessful treatment of splenic rupture in a haemophilic boy
}

\author{
B GIBSON，F W WRIGHT， C R RIZZA， N E DUDLEY
}

British Medical fournal, 1976, 1, 260-262

\section{Summary}

The recognition of traumatic splenic rupture in an 11-year-old severely affected haemophilic boy was delayed for over five weeks. Splenectomy was carried out successfully after the demonstration of splenic rupture by an isotope spleen scan. Splenic rupture is difficult to differentiate from more simple causes of retroperitoneal haematomata in haemophiliacs when there is no massive acute peritoneal bleeding, but it may be identified with isotopic spleen scans so long as the possibility of rupture is borne in mind.

\section{Introduction}

Rupture of the spleen has been reported in only a few patients with haemophilia, and in most the diagnosis has been delayed. In the absence of acute intraperitoneal bleeding with collapse and shock splenic rupture may be difficult to diagnose, even in non-haemophiliacs. In five patients with haemophilia the rupture was spontaneous or non-traumatic, ${ }^{1-4}$ two patients having concomitant infectious mononucleosis. In one case ${ }^{5}$ the diagnosis was made only at necropsy; the patient died 17 days after presenting with left upper quadrant pain. In this case, as in others, a rapid response to cryoprecipitate had clinically appeared to justify the diagnosis of a simple haematoma of the abdominal wall. In one post-traumatic case ${ }^{6}$ splenectomy was performed nine days after a road traffic accident.

We have seen a further patient with splenic rupture which we at first mistook for a retroperitoneal haematoma.

\footnotetext{
Oxford Haemophilia Centre and Departments of Radiology and Surgery, Churchill Hospital, Oxford OX3 7LJ

B GIBSON, MB, CHB, senior house physician (present address: Ninewells Hospital, Dundee)

F W WRIGHT, DM, FRCR, consultant radiologist

C R RIZZA, MD, FRCPED, consultant physician

N E DUDLEY, FRCs, consultant surgeon
}

\section{Case report}

On 30 November 1974 the patient, an 11-year-old boy with severe haemophilia (with a factor VIII level of $0 \%$ and no antibodies to human factor VIII), banged his lower chest against the back of the the front seat of his father's car when it struck the kerb with a jolt in parking. He did not complain of pain but felt sick and vomited. He then slept and awoke several hours later complaining of pain in the left hypochondrium. Subsequently he vomited several times, the vomitus containing blood. The next day he was admitted to his local hospital with pain in the lower abdomen. He was pale, with a pulse rate of $140 / \mathrm{min}$ and a blood pressure of $80 / 40 \mathrm{~mm} \mathrm{Hg}$. The lower abdomen was tender and both flanks dull to percussion. A chest radiograph showed no fractured ribs. Haemoglobin was $7 \mathrm{~g} / \mathrm{dl}$. He was transfused with $1500 \mathrm{ml}$ of whole blood and given 1200 units of human factor VIII, which raised his factor VIII level to over $60 \%$ of normal. He improved sufficiently to be transferred to Oxford. Although a diagnosis of splenic rupture was initially considered, it was not pursued in view of the history of minimal injury and the rapid recovery after the blood and factor VIII transfusion. He was thought to have a retroperitoneal haematoma and was given enough factor VIII to keep the level above $20 \%$ for the next two days. He improved considerably and was discharged on 11 December 1975, taking oral iron tablets.

He remained well for 12 days, attending school and some Christmas parties. On 23 December 1974 he was readmitted to hospital after passing two melaena stools. He was shocked (haemoglobin $3.3 \mathrm{~g} / \mathrm{dl}$ ) and was transfused with packed cells from $1500 \mathrm{ml}$ blood and given factor VIII to raise the level above $60 \%$ before again being transferred to Oxford. He denied any abdominal pain but was pale, ill-looking, and in mild congestive cardiac failure. His abdomen was slightly distended and there was tenderness in the left iliac fossa. A large mass was now palpable in the left hypochondrium. Plain radiographs of the chest and abdomen showed left basal collapse and a sizeable soft tissue mass beneath a somewhat raised left side of the diaphragm; the stomach gas bubble was not visible (fig 1a). Recurrence of a retroperitoneal haematoma was diagnosed. He was given factor VIII to keep the level at $30-60 \%$ for 48 hours, after which the doses were reduced. The melaena stopped and the mass appeared to shrink. A few days later the patient developed a left basal consolidation and pleural reaction (fig 1b). This was treated with amoxycillin. Despite radiological improvement he continued to have intermittent fever up to $38 \cdot 5^{\circ} \mathrm{C}$. $\mathrm{He}$ began passing watery stools containing small amounts of blood. Stool cultures were negative.

A steady rise in platelet and white blood counts continued. This was initially thought to be due to regeneration after blood loss, but since then the patient had been adequately transfused, was maintaing his haemoglobin level, and showed no overt signs of continuing haemor-

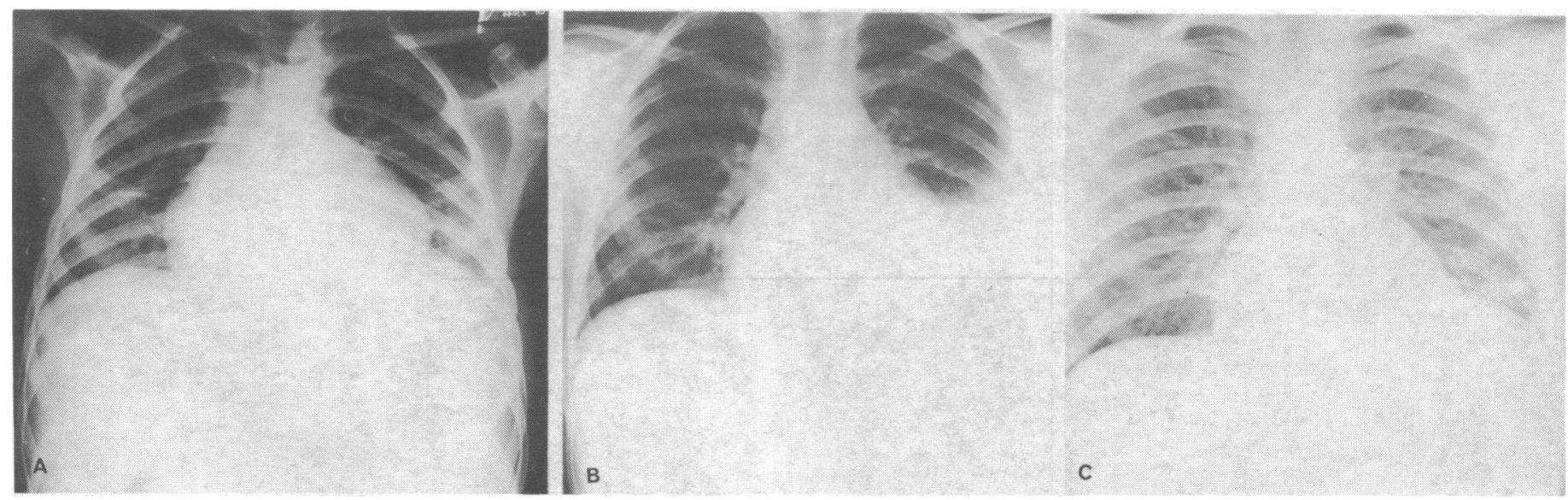




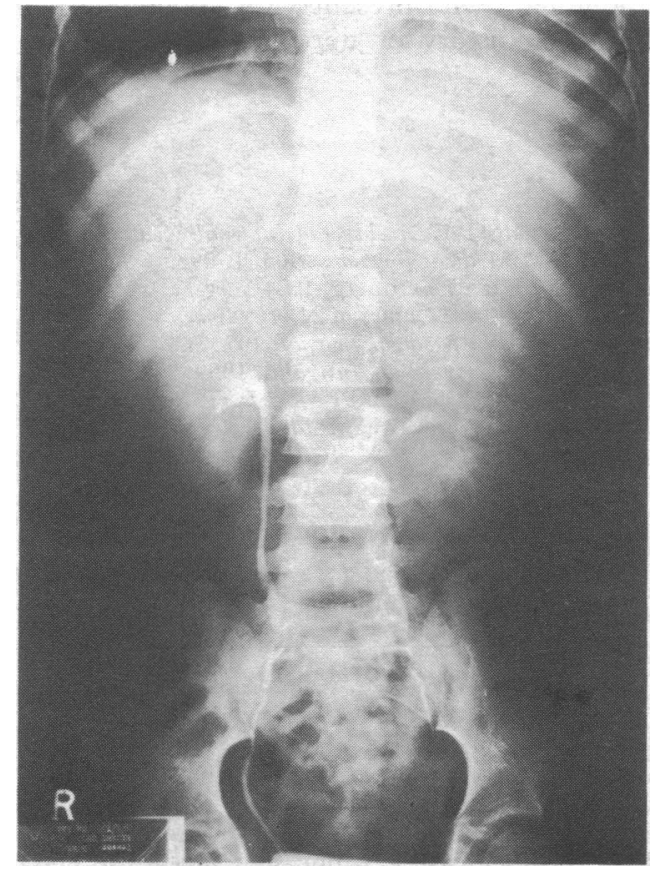

FIG 2-Intravenous pyelogram taken on 3 January 1975. Left kidney is displaced downwards by soft tissue mass in left upper quadrant. Note that stomach gas shadow overlies spine.

rhage. The left upper abdominal mass was still present and further radiological studies were undertaken to identify this.

A chest radiograph (fig 1c) showed that the left base had cleared. An intravenous pyelogram (fig 2) showed that there was a very large left upper abdominal mass and that the left kidney was displaced downwards by it. A gastrografin meal showed definite displacement of the stomach to the right. A liver and spleen scan, using ${ }^{99} \mathrm{mTC}$ - colloid and a gamma-camera (fig 3 ) indicated that the left side of the liver was a little compressed by the soft tissue mass, and that the spleen was in two parts, one in the normal place and the other displaced downwards and medially, indicating a ruptured spleen and a large haematoma.
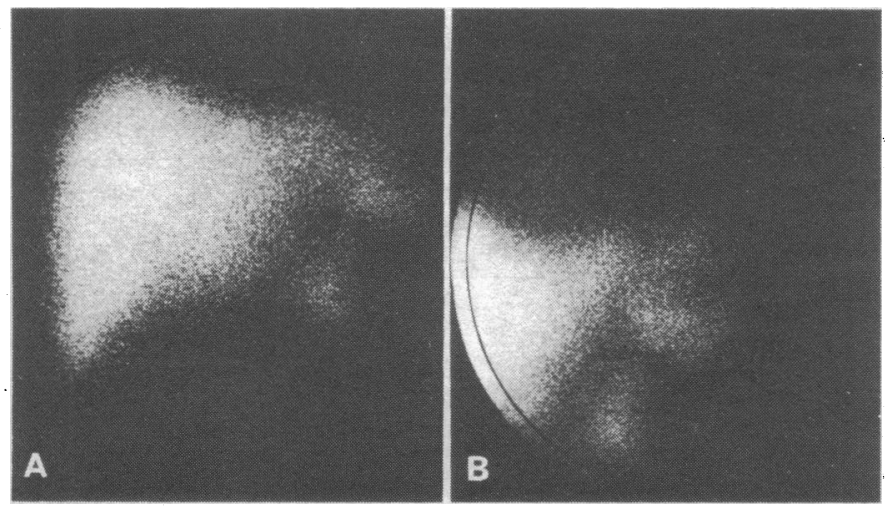

FIG 3-Liver and spleen scan (gamma-camera, polaroid prints) showing (a) liver and spleen, and (b) left side of liver and spleen. Spleen is clearly divided into two portions.

The rise in blood platelets also suggested damage to the splenic tissue.

Thirty-seven days after the original injury splenectomy was performed. Fibrinous adhesions were present between the mass and the anterior abdominal wall. The main bulk of the mass $(14 \times 9 \mathrm{~cm})$ was a large haematoma that adhered closely to the stomach and the transverse colon. About $200 \mathrm{ml}$ of altered blood was present in the left paracolic gutter. The colon was freed and the grossly thickened gastrosplenic and lienorenal ligaments divided to allow the spleen to be rotated forward. The splenic pedicle was completely surrounded by a soft haematoma which was undergoing autolysis. In consequence, the splenic artery and veins were exceedingly friable and all vessels had to be separately identified and double-ligated. Dissection of the mass from the greater curve of the stomach completed the procedure. The bisected spleen is shown in fig 4 .

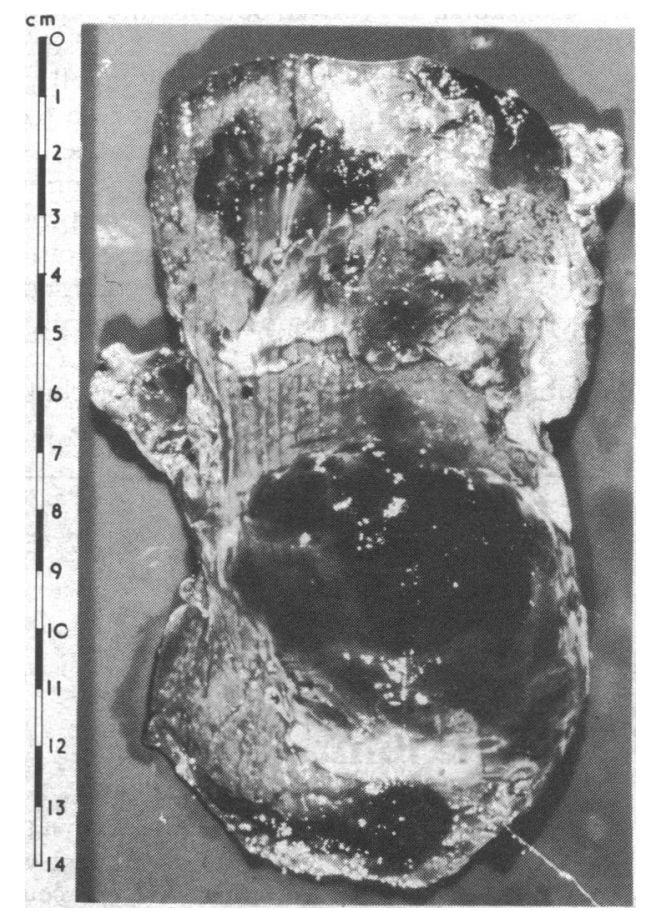

FIG 4-Bisected spleen showing intrasplenic haematoma.

Before operation the boy received enough factor VIII to raise his blood level to $80 \%$ and this was then maintained at $40-80 \%$ for one week and $20-60 \%$ for a further week. His postoperative course was uneventful.

\section{Discussion}

This case is of particular interest in two respects: firstly, because the patient was a severely affected haemophiliac and, secondly, because of the diagnostic difficulty in differentiating between a retroperitoneal haematoma-a relatively common complication in such patients-and concealed splenic rupture, a much less common occurrence.

The diagnosis of splenic rupture was delayed for several reasons. Firstly, the episode followed only a minor blow to the lower chest. Nevertheless, both splenic and renal injury can occur with relatively minor trauma. In normal children a minor injury to either organ will probably resolve, but in a haemophiliac continued bleeding may occur and the resultant haematoma may further rupture the organ. We have seen continuing bleeding from a kidney after similar minor trauma in a 10-year-old girl with factor IX deficiency ${ }^{7}$ but have not seen this with the spleen in a haemophiliac. Even a haematoma of the stomach wall ${ }^{8}$ may produce a large palpable mass in the left upper quadrant, and this must be considered as a possible site of bleeding in such patients. Even in a normal person, however, a splenic injury may continue to bleed for several days, leading to considerable delay in diagnosis, especially if the capsule of the organ is not ruptured. Indeed, a chronic haematoma may go on to form a chronic post-traumatic cyst of the spleen, which may continue to increase for several years. ${ }^{9}$ Although a mass in the left hypochondrium after injury may suggest splenic rupture, it is not uncommon for a retroperitoneal haematoma to become localised to this region. On both admissions our patient responded rapidly to blood transfusion and factor VIII replacement treatment, most probably because the rupture was incomplete. His haematoma was localised and clinically mimicked a simple 
retroperitoneal haematoma, but the patient did in fact have both.

In most patients with haemophilia with a retroperitoneal haematoma the haematoma resolves after factor viii transfusion and in most no radiological investigations, other than plain chest and abdominal radiographs, are carried out. Splenic rupture can be difficult to diagnose clinically even in a normal person in the absence of massive acuteintraperitoneal bleeding with collapse and shock. Fortunately, since spleen imaging using colloid particles with a radioactive label (taken up by the endothelial cells of the liver and spleen) is now readily available in most large centres, the problem is relatively easily resolved, provided that the possibility of the underlying rupture is considered. Demonstrations of splenic laceration by isotope imaging have been recorded, 41011 but such a wide separation of the fragments as occurred in our case has not been described.

Clearly the possibility of splenic rupture should be considered in all haemophiliacs who present with abdominal pain and in whom there is a history of upper abdominal or lower chest injury.

\section{References}

${ }^{1}$ Brook, J, and Newham, P E, Archives of Internal Medicine, 1965, 115, 595.

2 Smith, P H, British Medical fournal, 1965, 1, 296.

${ }^{3}$ Gowda, M, Vietti, T, and Ternberg, J L, Surgery, 1968, 64, 1119.

4 Baron, J M, et al, Surgical Clinics of North America, 1970, 50, 205.

5 Stout, C, et al, Southern Medical fournal, 1973, 66, 791.

6 Pitney, W R, Medical fournal of Australia, 1959, 1, 65.

${ }^{7}$ Wright, F W, Matthews, J M, and Brock, L G, Radiology, 1971, 98, 571.

${ }^{8}$ Wright, F W, and Matthews, J M, Radiology, 1971, 98, 547.

${ }^{9}$ Wright, F W, and Williams, E W, British fournal of Radiology, 1974, 47, 454.

${ }^{10}$ Merrick, M V, and Monahan, P R W, Injury, 1971, 3, 73.

11 De Land, F H, and Wagner, H N, Atlas of Nuclear Medicine, vol 3, p 228. Philadelphia, Saunders, 1972.

\section{SHORT REPORTS}

\section{Primary gout affecting the sternoclavicular joint}

Primary gout is rare in females and usually affects them after the menopause. ${ }^{12}$ We report the case of a girl who presented with an acute gouty arthritis of the right sternoclavicular joint. We could find no previous report of acute gouty arthritis affecting the sternoclavicular joint.

\section{Case report}

An 18-year-old girl was admitted to hospital with a three-day history of throbbing pain, swelling, and tenderness in the right sternoclavicular joint which had been treated with antibiotics. Examination confirmed these signs together with cellulitis over the joint. The other joints were normal, and no abnormality was found on general examination. Her temperature was $37.7^{\circ} \mathrm{C}$, the erythrocyte sedimentation rate $60 \mathrm{~mm}$ in $1 \mathrm{~h}$, and the white cell count $7 \cdot 4 \times 10^{9} / 1\left(7400 / \mathrm{mm}^{3}\right)$ with a normal differential. Pyogenic arthritis was diagnosed and the patient started on cloxacillin $500 \mathrm{mg}$ four times a day by mouth. Radiographs of the chest and both sternoclavicular joints were normal. Tests for serum immunoglobulins, antinuclear factor, rheumatoid factor, sheep cell agglutination titre, LE cell preparation, and serological tests (Wasserman, Kahn, and Reiter) for syphillis were also negative. The day after admission the affected joint was aspirated and $2 \mathrm{ml}$ of blood-stained fluid removed. Bacterial and tubercle bacilli cultures were negative.

The treatment effected little improvement in the joint. Five days after admission a routine biochemical screen showed a serum uric acid level of $0.67 \mathrm{mmol} / 1(11.3 \mathrm{mg} / 100 \mathrm{ml})($ normal $0 \cdot 15-0.45 \mathrm{mmol} / 1(2.5-7.5 \mathrm{mg} / 100 \mathrm{ml})$ ), which suggested a diagnosis of gouty arthritis. Serum uric acid levels remained consistently raised $(0.66,0.65 \mathrm{mmol} / 1(11.1,10.9 \mathrm{mg} / 100 \mathrm{ml}))$. The hyperuricaemia, negative culture of the joint aspirate, and lack of response to antibiotic treatment all pointed to a diagnosis of acute gouty arthritis. Unfortunately, the joint aspirate was not examined for urate crystals. There was no history of diuretic intake and no family history of gout or other joint disease. The serum uric acid levels of both parents were normal (father $0.36 \mathrm{mmol} / 1(6.0 \mathrm{mg} / 100 \mathrm{ml})$ and mother $0.21 \mathrm{mmol} / 1(3.6 \mathrm{mg} / 100 \mathrm{ml}))$. The patient showed no evidence of an associated cause of gout. Her bone marrow and serum levels of lactate, triglyceride, cholesterol and lipoprotein were all normal, as were also the serum creatinine and creatine clearance. Uric acid excretion was within normal limits $(2.8$ and $3.0 \mathrm{mmol} / 24 \mathrm{~h}(480$ and 500 $\mathrm{mg} / 24 \mathrm{~h}))^{3}$

The patient was given phenylbutazone $200 \mathrm{mg}$ and allopurinol $100 \mathrm{mg}$ three times a day by mouth. Two days later the joint greatly improved and the phenylbutazone was discontinued. The serum uric acid level returned to normal $(0.26 \mathrm{mmol} / 1(4.4 \mathrm{mg} / 100 \mathrm{ml}))$ and within a week the arthritis had completely subsided. The allopurinol was continued after discharge. After seven months there had been no recurrence of symptoms. Her serum uric acid and her renal function were within normal limits.

\section{Discussion}

Primary or idiopathic gout affects women in 3-7\% of cases. ${ }^{2}$ The typical initial attack is monoarticular, affecting the metatarsophalangeal joint of the big toe in at least $50 \%$ of cases. ${ }^{2}$ When another joint is the one affected diagnosis may be delayed for a long time. ${ }^{4}$ Durward, 5 analysing 1012 cases of gout, found that $48.6 \%$ of the cases of primary gout were admitted as emergencies and that $40 \%$ of these were misdiagnosed. Among the erroneous diagnoses were haemarthrosis, cellulitis, osteoarthritis, pyogenic arthritis, and fractures. The fact that the sternoclavicular joint was affected in our case resulted both in a misdiagnosis and in a delay in diagnosis of five days. Among the rarer joints to be affected are the sacroiliac, lumbar spine, atlas vertebra, and the lower thoracic spine. ${ }^{1}$

We thank Mr J G Mathews for permission to report this case.

Requests for reprints should be sent to Dr G R Sant.

${ }^{1}$ Cohen, H, and Bywaters, E G L, in Textbook of The Rheumatic Diseases ed W S C Copeman, 4th edn, p 428. London, Churchill-Livingstone, 1969.

2 Wyngaarden, J B, and Kelley, W N, in The Metabolic Basis of Inherited Disease, ed J B Stanbury, J B Wyngaarden, and D S Fredrickson, 3rd edn, p 889. New York, McGraw Hill, 1972.

3 Seegmiller, J E, et al, fournal of Clinical Investigation, 1961, 40, 1304.

$4 \mathrm{Jaffe}, \mathrm{H} \mathrm{L}$, in Degenerative and Inflammatory Diseases of Bones and foints, ed H L Jaffe, p 479. Lea and Febiger, 1972.

${ }^{5}$ Durward, W F, Scottish Medical fournal, 1973, 18, suppl 1243.

Department of Surgery, Mercer's Hospital, Dublin 2

GRANNUM R SANT, MB, BAO, senior house officer ERNESTO DIAS, FRCSI, registrar

\section{Prolactin and human red blood cells}

Histochemical studies ${ }^{1}{ }^{2}$ suggest that rat and human red blood cells may bind prolactin. The human results were dismissed as artifacts, but we have evidence that this interpretation may have been incorrect. ${ }^{2}$ Our findings have important practical implications for the processing of blood samples for prolactin estimations.

\section{Method and results}

Blood samples were taken at 10 am from 10 normal women and 9 normal men and aliquots were spun down either immediately or after incubation at various time intervals up to five days at $4^{\circ} \mathrm{C}, 22^{\circ} \mathrm{C}$, and $37^{\circ} \mathrm{C}$. Plasma samples 